\title{
Imaginarios rurales: el modelo de afincamiento en la Planificación Rural del Uruguay de Gómez Gavazzo
}

\section{Lucio de Souza}

Profesor de la Facultad de Arquitectura Diseño y Urbanismo de la Universidad de la Republica. Montevideo [Montevideo] Uruguay. < desouzalucio@gmail.com>

\section{Resumen}

Entre 1934 y 1952 el Arquitecto Carlos Gómez Gavazzo desarrolla un enfoque de las problemáticas rurales de Latinoamérica y en particular de nuestro país. Ampliando la escala de las preocupaciones, pasa de problematizar la unidad de hábitat familiar del campo a una completa teoría sobre el modo de ordenar la totalidad del territorio productivo rural. Este decurso va acompañado de una formulación precisa de un imaginario radicalmente alternativo al habitual de los trabajadores rurales. Esta tesis busca probar que las condiciones del hábitat propuestas para el ámbito conformarían una red de localizaciones de pequeña escala, de alta densidad y equipada con buen nivel de servicios, es decir, un imaginario netamente urbano para la vida en el campo. Para ello se analizará el proceso de construcción de la problemática rural y se tomará por caso el proyecto para el centro colónico de Chapicuy de 1953.

\section{Palavras-chave}

Gómez Gavazzo. Planificación rural. Imaginarios.

\section{Rural imaginaries: the model of settlement in the Rural Planning of Uruguay by Gómez Gavazzo}

\begin{abstract}
Between 1934 and 1952 the architect Carlos Gómez Gavazzo develops an approach to rural problems of Latin America and particularly in our country. Expanding the scale of the concerns, he goes from the unit family farm habitat to a complete theory on how to order the entire rural productive territory. This path is accompanied by a precise formulation of a radical alternative to the usual imagery of rural workers. This thesis seeks to prove that the proposed habitat conditions for field locations would form a network of small-scale, high density and equipped with good level of service, ie a distinctly urban life in the countryside imaginary. For this, the process of building rural issues will be discussed and proposed for colonic center Chapicuy 1953 will be taken by case.
\end{abstract}

\section{Keywords}

Gómez Gavazzo. Rural planning, Imaginary. 


\section{La construcción del problema del afincamiento rural}

Frente a un auditorio integrado entre otros, por el Ministro de Instrucción Pública, el Ministro de Relaciones Exteriores, el Representante de la Junta de Asistencia Técnica de Naciones Unidas, el Embajador de Ecuador y un grupo de becarios de la ONU, Gómez Gavazzo presenta en 1953 con gran claridad, las razones por las cuales debe hablarse de Planificación Regional desde la Arquitectura. La necesidad de atender el bienestar de las comunidades, hace que ya no sea posible hablar de las ciudades aisladas [del Urbanismo], sino entender las existencias relacionadas del "medio consumidor" [lo urbano] y el "medio productor" [lo rural].

La oportunidad de experimentar y llevar a la práctica las ideas desarrolladas durante unos 20 años de investigaciones, si contamos su origen en el rancho Experimental de San José de 1934, se hace casi posible al año siguiente. En 1954 el ITU entrega al Instituto Nacional de Colonización un profundo trabajo de análisis de la Ley de Colonización [Ley 12.029 de 1948] y las determinantes para el planeamiento, aplicado a las áreas de Chapicuy y Tangarupá, al noroeste del país. Junto a esto desarrolla un proyecto específico y detallado para el "centro colónico" de Chapicuy, el cual no se concretará.

Un poco más adelante en el tiempo, en 1959, estas ideas se transforman en un mecanismo teórico universalmente válido y extensible a todo el territorio nacional. En el Primer Congreso Nacional ProReforma Agraria el informe de la Comisión que integraba Gómez Gavazzo declara necesario [...]

[...] la formación de núcleos colónicos emplazados convenientemente para provocar, en forma directa e indirecta un desarrollo regional, sin que ello signifique descuidar las distintas formas de colonización aislada (Gómez Gavazzo, 1959).

Parecería como si mediante un juego de espejos deformantes, las dificultades que la empresa particular tuvo, alimentara las expectativas a extremos inusitados y llevara a creer posible una transformación racionalmente planificada de todo el territorio nacional. Este largo proceso de construcción del problema del afincamiento rural, recorre extensos plazos de reflexión y de acopio de información, mediado por hitos significativos a manera de súbitas epifanías. Esta evolución obviamente no está aislada de las ideas y teorías que se venían construyendo en América Latina de la mano de las visiones del desarrollismo de Prebisch asociadas a la tesis sobre el deterioro de los términos de intercambio y la necesidad del impulso de los Estados a la planificación de su desarrollo. Este trabajo presenta una narrativa razonada de ese transcurso, sabiendo que toda narrativa implica un proceso hermenéutico controvertido. Pasemos a verlo.

\subsection{El Rancho Experimental de San José [1934]}

La experiencia del Rancho de San José está enraizada en el problema de la habitación rural y la propiedad de la tierra. Esta cuestión no puede aislarse de una problemática propia de toda Latinoamérica [aunque hiciera eclosión de manera diferente y en distintos momentos según las regiones] que guarda relación con la rápida apropiación de las tierras productivas ocurrida en pleno proceso de colonización. Con el posterior alambramiento y la incipiente modernización conservadora, se alimentó una creciente cantidad de población de trabajadores rurales asentados en condiciones paupérrimas. Esto impulsó reclamos de reforma agraria y distribución de tierras, que si bien tuvieron algunas respuestas desde los Estado, nunca llegaron a transformar crucialmente la realidad. La cuestión de la vivienda insalubre rural está asociada a la propiedad de la tierra como se planteaba ya desde los iniciales posicionamientos teóricos del economista agrario ruso Aleksandr Chayánov, que planteaba una imprescindible transferencia de la tierra a los trabajadores rurales organizados de modo cooperativo, en plena revolución comunista.

También en el Uruguay del cambio de siglo, uno de los tópicos de debate fundamentales, tiene que ver con el modo de vida de las poblaciones rurales: ya por el año 1869 el Presidente de la República Lorenzo Batlle mencionaba "que si la ciudadanía se acordaba exclusivamente a los alfabetizados, solamente el 4\% de los habitantes de la campaña tendrían aquel derecho" (Rama, 1971). Bastante más adelante en el tiempo el Arq. Juan Antonio Scasso en la introducción a la publicación del Rancho Experimental en La Propaganda Rural menciona que [...] 
[...] no hay estadísticas en nuestro país que traduzcan fielmente la verdad en cifras, pero puede establecerse sin temor a ser inexactos que apenas un porcentaje irrisorio de habitantes de tierra adentro, cuenta con una vivienda aceptable (Scasso, 1935).

Esta cuestión será un problema que acompañará al desarrollo del Uruguay rural durante todo el siglo XX, manteniendo altos niveles de inadecuación en la vivienda que se manifiestan en los índices medidos en las diferentes épocas. Así por ejemplo, para 1949 se estimaba, en base a datos del Ministerio de Salud Pública, que casi el 17\% de la población del país residía en viviendas consideradas insalubres (MSP, 1949).

Acerca del tema del rancho tanto Scasso como Gómez Gavazzo coinciden en encontrar para la Arquitectura un compromiso ineludible. Para el primero [...]

[...] el arquitecto debe orientar preferentemente su atención al problema de la vivienda, pero no al de la vivienda de las clase pudientes o medianamente retribuidas, sino a la vivienda del obrero ciudadano, del trabajador rural, de los pobres y los más pobres [...] (Scasso, 1935), [...]

[...] mientras que para el segundo

[...] aún en algunos círculos es corriente considerar la arquitectura como una práctica creadora vinculada a la erección de viviendas y así también se la discute como un artículo de lujo. Si en lo primero pudiera caber algo de razón, debe negarse terminantemente lo segundo (Gómez Gavazzo, 1934).

Este compromiso se traduce en un estudio presentado por Carlos Gómez Gavazzo y Teófilo Herrán a la Primera Reunión Anual de Arquitectos Nacionales en 1934. Sobre la base de las conclusiones de dicho estudio la Intendencia de San José encomienda la realización de un prototipo para la Exposición Ganadera, Agrícola e Industrial.

El Rancho modelo es un ejercicio de fuerte racionalización de las condiciones ambientales, distributivas y funcionales, no exento de un homenaje al modo de construir usual. Las técnicas son las tradicionales (madera, paja y barro) pero la distribución racional y la insistencia en el higienismo (el sol, los vientos, la vegetación, etc.) lo convierten en un epígono moderno de su antecesor.

Figura 1. Rancho experimental de San José; planta general (a la izquierda) y fotos del prototipo (a la derecha).
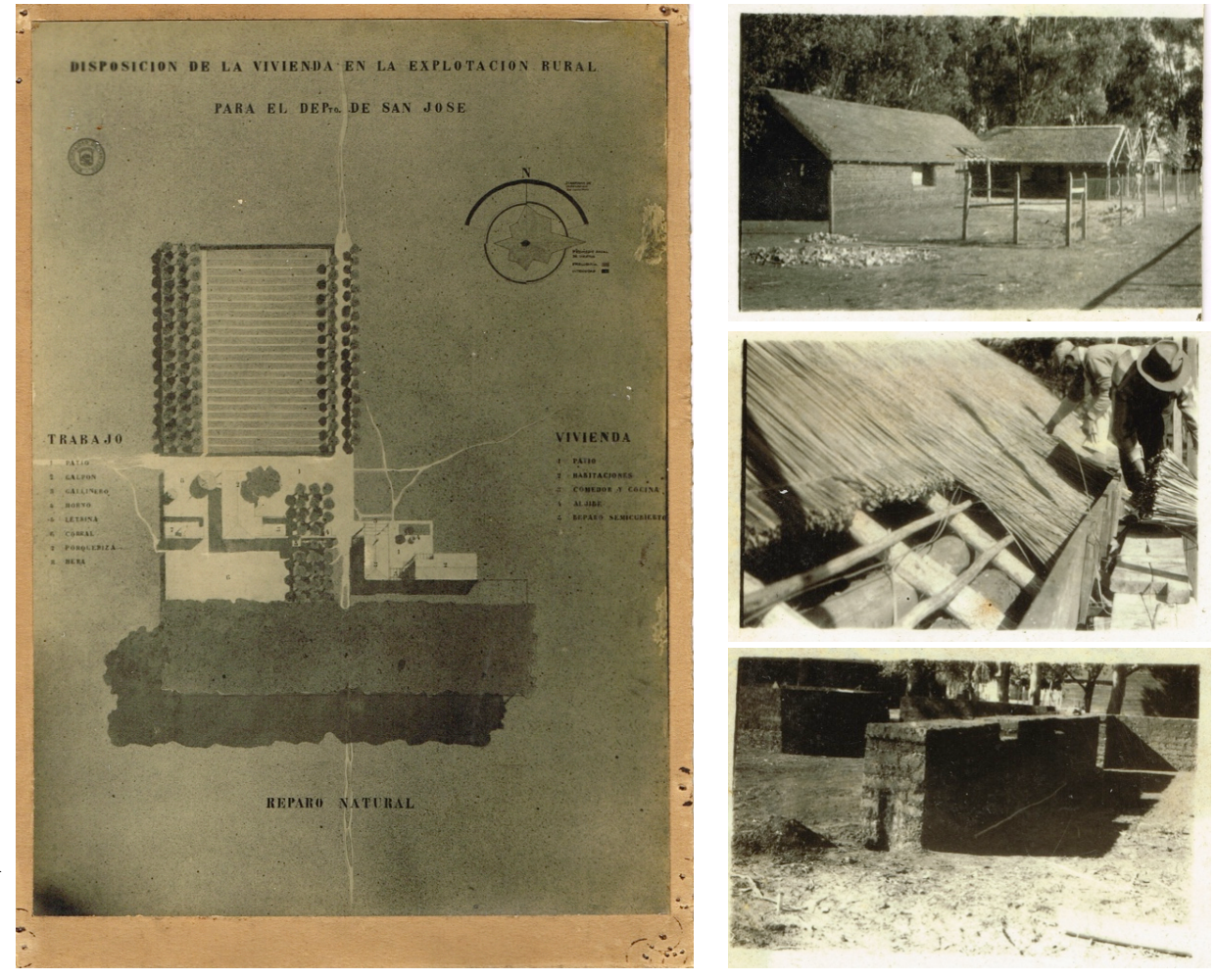
En definitiva, era posible y deseable "mejorar" los modos de hacer y las convenciones del ámbito rural. Este mejoramiento debía provenir de una mirada racional-cientificista del problema. Sin embargo la mirada del experto debía dejar lugar a la mirada "experiente" que el hacer del habitante rural había desarrollado durante largo tiempo.

\subsection{El Primer Congreso Nacional de Colonización}

Entre el 19 y el 22 de mayo de 1945, mientras finalizaban los estertores de la guerra en Europa, se reunía en Paysandú - al noroeste uruguayo - el Primer Congreso Nacional de Colonización, para debatir y realizar propuestas acerca de otro de los cruciales problemas nacionales: el campo despoblado e inculto, está sometido a la tenencia latifundista mientras los campesinos minifundistas viven en la miseria sin poder tecnificar ni desarrollar sus pequeños emprendimientos productivos.

Varios proyectos de Ley ${ }^{1}$ intentaron enfrentar esta situación mediante la creación de una Institución específica, mediante el cobro de impuestos o el orden de preferencia para el Estado en las compras de tierras, etc. Sin embargo las soluciones no avanzaban y la realidad seguía su transcurso indefectible.

Gómez Gavazzo, enviado como representante de la Facultad de Arquitectura, comienza su intervención con una pregunta retórica: [...]

[...] Muchos de los que me escuchan se habrán preguntado ¿qué intervención puede tener el arquitecto en un tema agrario, que no sea el que corresponde a la disposición, emplazamiento y construcción del hábitat rural? (Gómez Gavazzo, 1945).

Y continúa con una singular alocución cargada de poesía y metáforas, poco común para su estilo, en general seco y concreto: [...]

[...] formas y espacios aparecen por doquier matizando infinitamente el goce y las penurias del hombre. Individuos y sociedades usan por así decir, de las formas y espacios cantando y llorando a la naturaleza en el fárrago de sus propias imperfecciones y en la lucha por un mejor vivir [...] y como en los cuentos - alegría y dolores - matizan su ritmo preñado de ripios y estrofas enloquecedoras que crean de paso ideales múltiples, algunos definidos, otros vagos [...] (id., ibid.).

Al finalizar su discurso queda más claro su enfoque: [...]

[...] Los poetas y pintores crean a su antojo paisajes hipotéticos. El Arquitecto debe conformarse con tender paisajes reales [...] no podrá nunca entonces del paisaje sustraerse al hombre [...] y afrontar con sus funciones y su técnica un complemento que modele un todo con él [...] El campo después de lo visto, puede ser considerado inequívocamente como una parte del paisaje -el hombre en el agro-su habitación, la producción y el consumo es un fenómeno regulable (id., ibid.).

La intervención en el Congreso impulsa la creación de una nueva Comisión no prevista en el Reglamento, que es aceptada, conformada y obviamente presidida por Gómez Gavazzo: la Comisión de Ordenación Integral del Agro. La iniciativa principal de la Comisión es proponer al Congreso como Resolución: [...]

[...] la creación de un organismo competente de Planificación que debe estudiar a la brevedad posible y con carácter urgente, el planeamiento nacional como método único capaz de orientar y coordinar el estudio integral de todos los problemas sociales, económicos y técnicos del agro (id., ibid.).

\footnotetext{
${ }^{1}$ Véase por ejemplo el de Emilio Frugoni de setiembre de 1940 "Instituto de Colonización y Reforma Agraria” o el del "Impuesto a la explotación latifundista" de los diputados Lamas, Malet y Castellanos de 1951.
} 
Ahora si, respuesta obtenida: el Arquitecto viene a intervenir en un tema agrario en su rol de organizador y planificador integral... nada menos.

\subsection{Remodelación del Naranjal Salteño}

En octubre de 1945, cuando redacta el informe final sobre su participación en el Congreso (que presenta al Decano de la Facultad de Arquitectura, en ese entonces Leopoldo Carlos Agorio), Gómez Gavazzo menciona como uno de los antecedentes acerca de la temática rural, "un ejercicio de arquitectación [sic] de una explotación frutícola" (Gómez Gavazzo, 1945). Se trata de un trabajo que le fuera encargado alrededor de 1944 por la familia Solari, propietaria de naranjales en Salto al noroeste del Uruguay y cuyo objetivo era mejorar la producción frutal, aplicando técnicas científicas al estudio climático y geológico de los suelos productivos.

Del estudio se conservan unas 186 páginas de relevamiento del estado de cada una de las plantas existentes, clasificadas como "en producción", "plantas chicas", "a reponer" y "sin plantar". Todo esto en dos versiones, las originales del relevamiento y otras redibujadas por sectores donde se establece el porcentaje que cada categoría presenta. Este relevamiento constituirá luego el plano base del dibujo definitivo que la transformación propone.

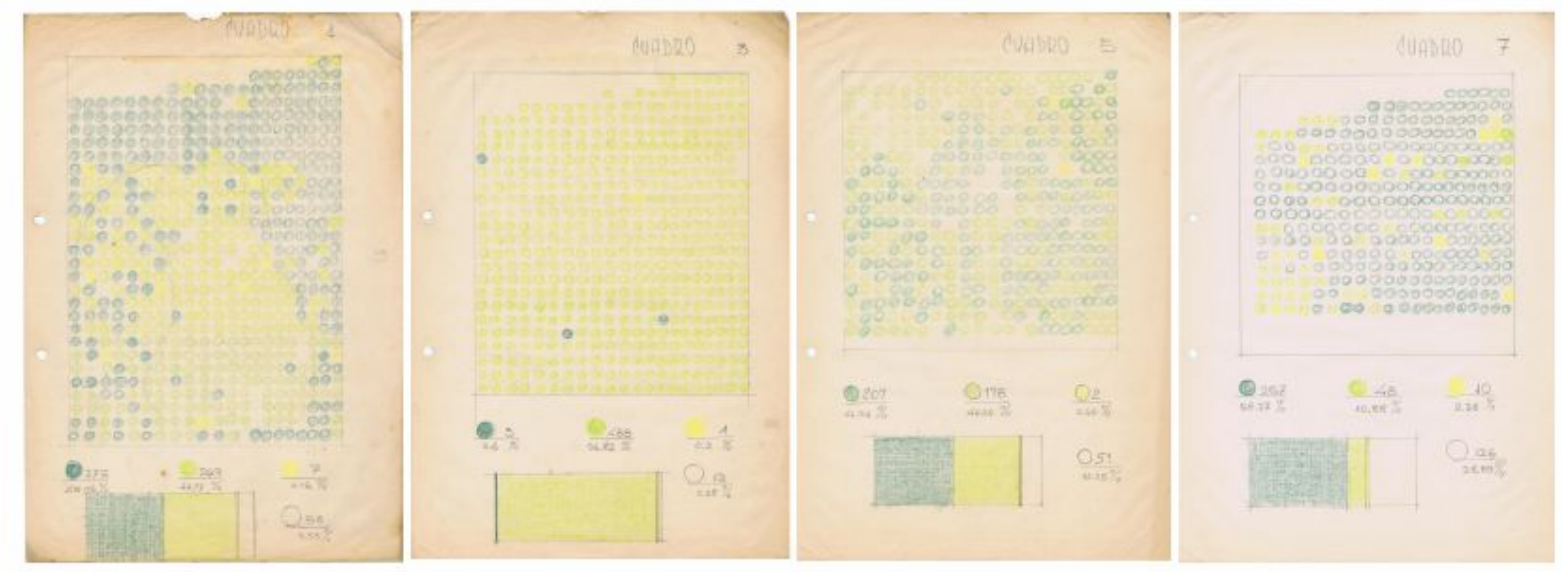

Figura 2. Ejemplos de planchas de estudio de la situación de las plantas.
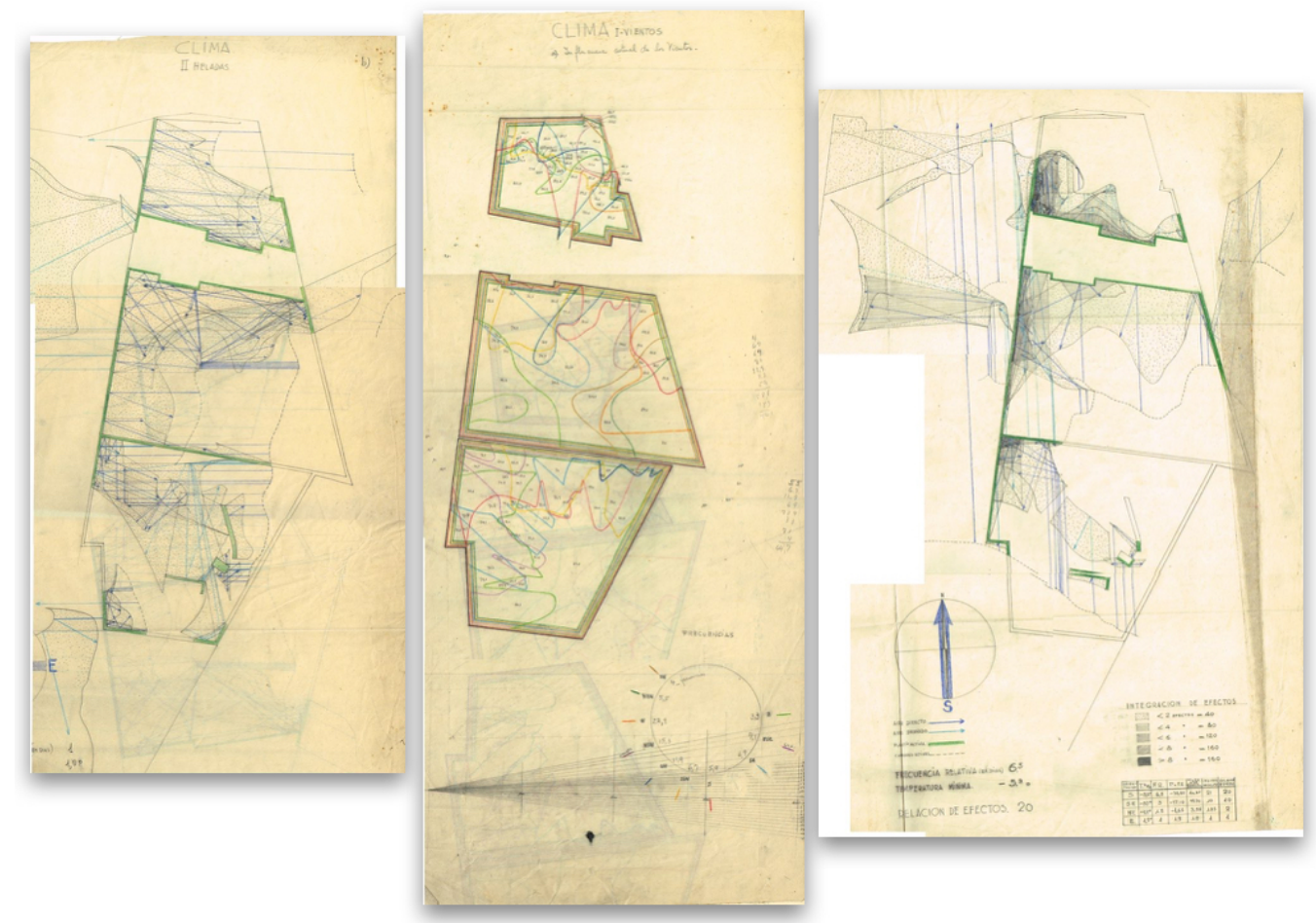

Figura 3. Ejemplos de láminas de estudio de vientos. 
Estos gráficos vienen acompañados en la carpeta de trabajo por unas 6 láminas de estudio de la influencia de los vientos predominantes y su correspondiente "integración de efectos". Estos estudios permitían establecer zonas de aires fríos nocturnos que habilitaran la formación de escarchas y heladas, lo cual podía dañar las plantas. En función de esa delimitación, era posible zonificar el área cultivada. Es decir, aplicar la herramienta básica del urbanismo moderno a un suelo eminentemente rural. Incipiente aparición de la disciplina denominada más adelante como "ruralismo", a manera de espejo del "urbanismo".

El objetivo de todos estos estudios era regular científicamente las variaciones climáticas de manera de favorecer el desarrollo de las plantas. Los medios serían: la forestación perimetral y mediante bandas que aíslen sectores; el cultivo en terrazas siguiendo la pendiente del suelo; la delimitación de senderos; y la localización de la mano de obra a distancias adecuadas a su zona de trabajo.

Adicionalmente se agrega en el listado de principios que guían el trabajo un punto singularmente significativo por la anticipación que presupone para la Teoría de la Planificación Rural:

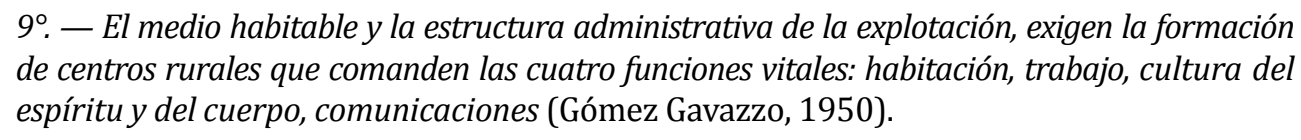

Esta afirmación resulta particularmente curiosa dado que el proyecto realizado abarcaba 250 Há., previendo una posible ampliación a 500 Há. Las dimensiones de la plantación no hacen razonable especular en la necesidad de equipamientos y servicios de tipo urbano, a menos que se estuviera pensando en una extrapolación del modelo. Debe recordarse que la plantación se ubicaba a poca distancia de la ciudad de Salto, la segunda en población del país por esas épocas, con lo cual existía disponibilidad de equipamientos en las cercanías. Quizá el ejercicio de arquitectación inicial estaba permitiendo prefigurar como modelo para el ruralismo, una red de localidades productivas pequeñas, distribuidas racionalmente sobre el territorio.

\subsection{La Planificación Territorial}

Tal como se acaba de mencionar, el pasaje de la preocupación centrada en las problemáticas de la ciudad hacia las de todo el territorio (comenzando por la región) también alimenta la conformación de una nueva manera de mirar la vida rural.

La ciudad ya no es un hecho aislado, por cuanto su existencia se reconoce subordinada a un medio productor, que debe responder con eficiencia a los requerimientos que ella misma, por naturaleza no puede satisfacer. El campo y la comunidad rural, desbordan las posibilidades del urbanismo y el ruralismo aporta ahora, a la planificación urbana, el concepto de la unidad integral (Gómez Gavazzo, 1953).

Esta idea de la superación del urbanismo — ciencia, según Gómez- que él mismo había visto nacer, por la necesaria inclusión de otra ciencia que enfocara en las problemáticas rurales (el ruralismo), le permitía mediante una operación dialéctica fundamentar una nueva disciplina: el Planeamiento Territorial. Es indiscutible que este modo de definir el nuevo campo disciplinar, alineado con las reflexiones sobre el tema en América y Europa (Mumford y Gueddes entre otros), parte de operar mediante un barrido escalar. La Arquitectura tiene la obligación de enfocar las problemáticas regionales para poder resolver adecuadamente las más cotidianas, como por ejemplo las habitacionales.

La reflexión sobre el tema se profundiza en un cuadro que figura en el Boletín Informativo del ITU de 1962. Allí se hace un esfuerzo por presentar de manera sucinta la evolución de la técnica planificadora desde 1900 hasta 1960. Algunas cuestiones significativas tienen que ver con el "calendario" apareciendo el 40 como el inicio de las preocupaciones regionalistas y el 50 como la expansión hacia la nación completa.

El urbanismo-ruralismo ya es presentado como "Planeamiento Territorial" en una conferencia dictada en el "Seminario para Planeamiento" de Tucumán, Argentina en 1961. [...] 
[...] y aquí, en esa oposición entre urbanismo y ruralismo, nace lo que hoy conocemos como ciencia del planeamiento territorial, haciendo de urbanismo y de ruralismo capitulos de esta nueva visión de organización de comunidades (Gómez Gavazzo, 1961).

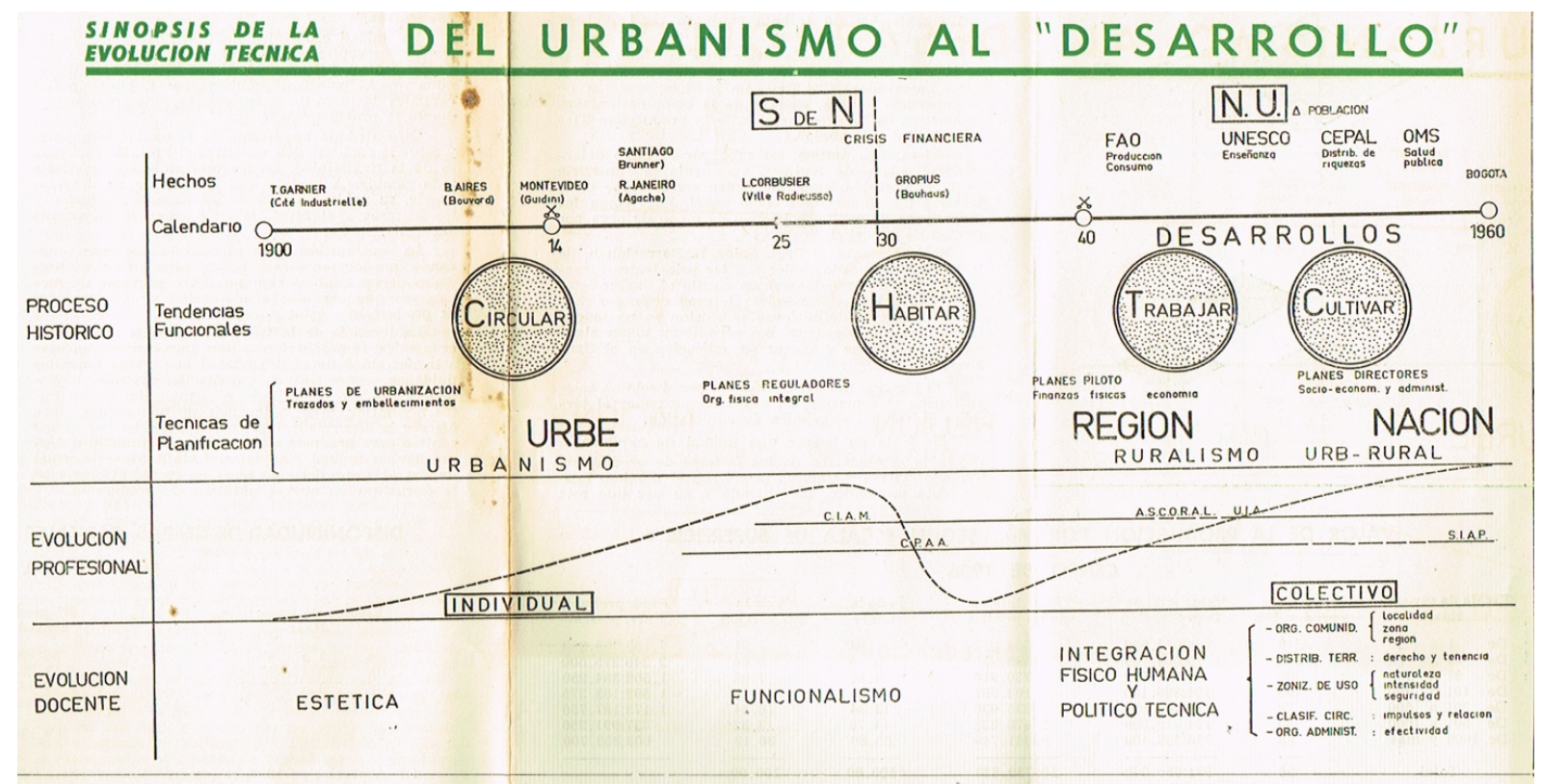

Figura 4. Boletín Informativo №23, abril 1962.

Los becarios de la ONU que venían al ITU a adiestrarse en técnica de Planificación, participaron entre otras cosas, del estudio de la zona rural y centro pecuario de Cerro Chato (1954). Adicionalmente concurrieron a las oficinas técnicas municipales y a un viaje de estudio a la zona productora del litoral uruguayo. Es decir, estudiar y analizar sistemáticamente lo rural-productivo en igualdad de valor con lo urbano.

No hay ninguna duda que esta mirada, directamente emparentada con las visiones geddesianas, fue incorporada en la disciplina tanto en Uruguay como en gran parte de Latinoamérica por los discursos y la difusión permanente que Gómez desarrolló desde el ITU. No en vano se reconoce en otros países [...]

[...] los aportes subsecuentes del Instituto de Teoría y Urbanismo, ITU, de la Facultad de Arquitectura de la Universidad de la República, consolidado como referente continental gracias a la obra de clasificación exhaustiva del equipo dirigido por Carlos Gómez Gavazzo, cuyos trípticos circulan por todas las oficinas de Urbanismo (Gurovich, 2009).

También es claro que gran parte del debate general de la época en Latinoamérica y el mundo ya había consensuado y definido a la Planificación del Desarrollo como la gran herramienta para transformar la realidad económica y social. La CEPAL desde 1948 promovía estos postulados y es en la Conferencia de 1961 del Consejo Interamericano Económico y Social (CIES) cuando se acuerda y se oficializa a manera de documento, en la Carta de Punta del Este, las líneas de pensamiento del Desarrollo asociado a la Planificación. Por la misma época la encíclica Mater et Magistra (1961) promulgada por el Papa Juan XXIII, presenta una serie de coincidencias importantes respecto de la temática, anunciando gran parte de las orientaciones de la Teología de la Liberación. Ésta última corriente, establecía fuertes vínculos conceptuales con la Teoría de la Dependencia, también arraigada en la CEPAL de Prebisch.

\section{El giro empírico}

Las visiones, incipientes que Gómez Gavazzo tenía acerca de la problemática del afincamiento rural, comienzan a dar un giro hacia la construcción definitiva del Imaginario Rural alrededor del inicio de los años 50. En particular a partir de dos acontecimientos significativos que analizaremos: la aprobación de la Ley de Creación del Instituto Nacional de Colonización en 1948 —en particular 
por los análisis que elabora de ella- y su participación en el Seminario Regional de Asuntos Sociales en Porto Alegre de 1951.

Ambos acontecimientos le permiten visualizar alternativas claras para enfocar el problema rural mientras se ordenan los pensamientos en torno a los métodos y procedimientos con los cuales poner en práctica dichas alternativas.

Curiosamente están entrelazados por líneas de pensamiento que guardan relación con un posicionamiento moderno más radical y que toma en particular a la grilla CIAM, de reciente elaboración en Bridgewater 47, como guía de estudio y exploración. La grilla aparece como mediadora intelectual en una problemática muy compleja que resultaba imposible de abarcar en su totalidad.

\subsection{La ley del Instituto Nacional de Colonización}

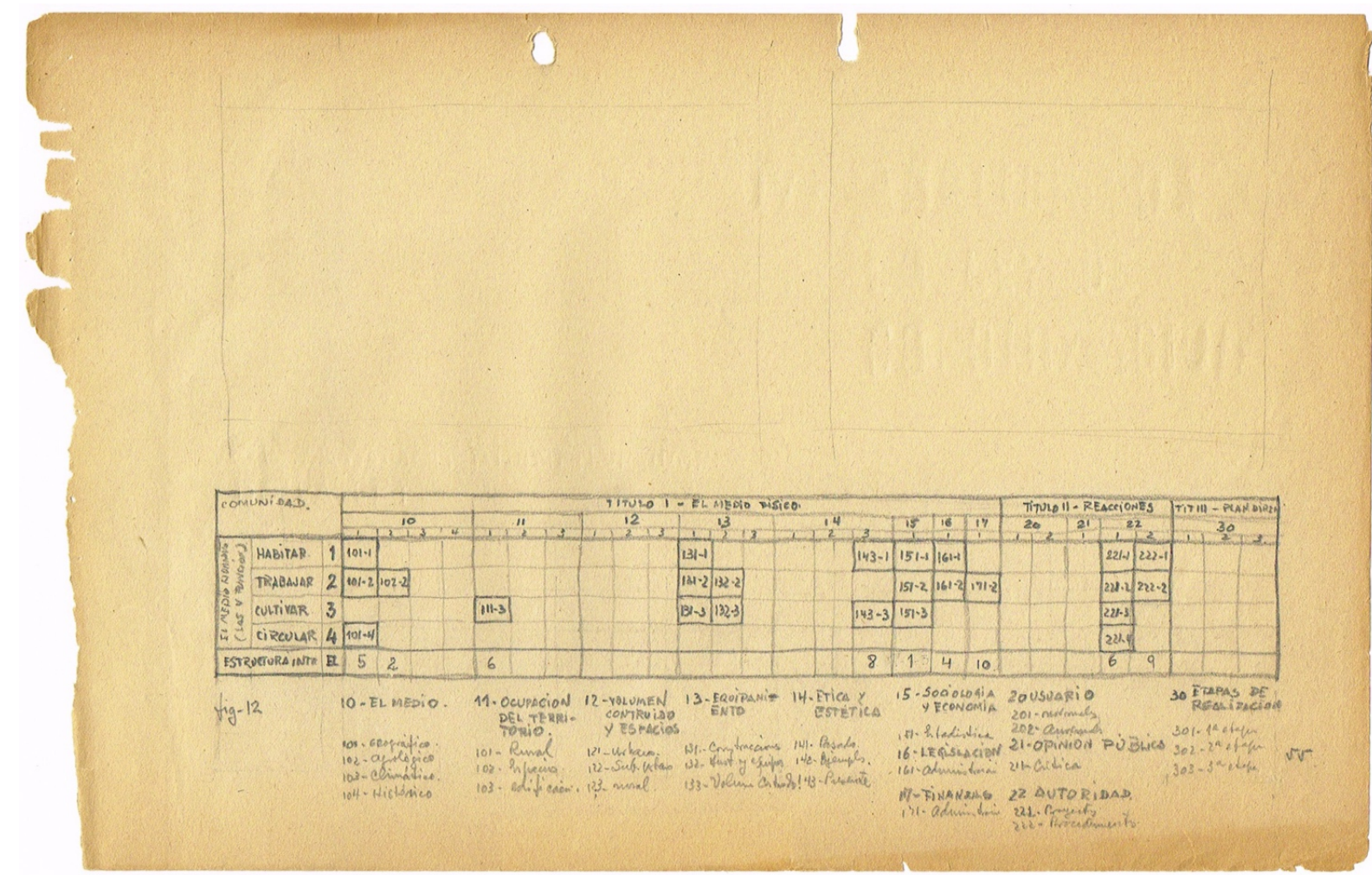

Figura 5. Ejemplo del análisis de la Ley 11.029 mediante la Grilla CIAM.

La Ley 11.029 del 12 de enero de 1948 crea el Instituto Nacional de Colonización, una aspiración de los sectores políticos progresistas que buscaban mecanismos legales suficientemente poderosos para revertir en el mediano plazo, los procesos históricos de expansión del latifundio. Para ello se apostaba a la figura de la colonización, es decir a la promoción de la localización en ámbitos rurales de la población trabajadora del campo, la cual venía siendo expulsada hacia los rancheríos y hacia las periferias descalificadas de las grandes ciudades. El Artículo $1^{\circ}$ lo establece claramente:

"A los efectos de esta ley, por colonización se entiende el conjunto de medidas a adoptarse de acuerdo con ella para promover una racional subdivisión de la tierra y su adecuada explotación, procurando el aumento y mejora de la producción agropecuaria y la radicación y bienestar del trabajador rural" (Uruguay, 1948).

La Ley crea una institución para llevar adelante esta política y establece los procedimientos y mecanismo para ello.

Sin embargo, lo realmente interesante de la Ley, consiste en una gran cantidad de detalles y definiciones que define acerca de las formas de la colonización, gran parte de las cuales permiten a Gómez Gavazzo establecer un mecanismo de retroalimentación con sus ideas. Por un lado toma 
aspectos de la Ley y los convierte en conceptos geométricos y ordenadores precisos y por otro lado construye doctrina sobre la manera de leer la Ley. En definitiva convierte el novel cuerpo legal en una Teoría.

Para ello, el primer ejercicio tiene que ver con un análisis profundo de todos los artículos de la Ley haciéndolos pasar por la Grilla CIAM. Una operación bastante curiosa de desmenuzamiento de todos los componentes del articulado, para ser ubicados en la trama de la grilla según los temas que trata. Este trabajo le permite descomponer la letra legal en piezas que hacen directa referencia a aspectos de Habitación, Trabajo, Cultivo del cuerpo y el espíritu y Circulación. Ésta no es una operación caprichosa, sino que está avalada por el propio texto que permite identificar aspectos de distancias, densidades, tamaños, tipos de actividad productiva, etc. Todos datos que son retomados de la legislación y puestos en su correspondiente casillero de análisis.

El análisis que elabora, ya como Director del ITU en el entorno de fines del año 1952, es ordenado y armado para constituir una publicación que nunca fue editada. Sin embargo se conserva el original mimeografiado así como los borradores para su ejecución.

Este pasaje por la grilla CIAM le permite desarrollar luego una serie de análisis de la Ley que definen minuciosamente aspectos significativos de la Teoría de la Planificación Rural:

- Los Equipamientos colectivos que las colonias deben tener diferenciados entre los comunes a todas, cualquiera sea el tipo de producción y los específicos de cada una según su carácter. Así por ejemplo "instalaciones para servicios colectivos de sanidad" o "recepción, clasificación, enfriado, transporte en colonias lecheras". Aquí comienzan a aparecer algunos de los rasgos singulares, de la Teoría alimentada por el imaginario que Gómez Gavazzo promueve. Se lee en el listado componentes como "Salas de cine, espectáculos y conferencias", "Club de niños y jóvenes", "Biblioteca", "Sala de fiestas y reuniones", "Policlínica", "Edificio para huéspedes", "Fábrica para producción de fertilizantes" o "Bosque ornamental". Todas unidades del programa que hacen referencia a un modo de vida más cercano a lo urbano que a lo rural. En particular si tomamos como comparativo el estilo de vida de la población que podía realojarse desde un pueblo de ratas de la época a estas nuevas colonias.

- También estudia de manera minuciosa el problema del tamaño ideal de lo que denomina la "unidad poderal". Es decir la dimensión más adecuada para la porción mínima de suelo asociada a un productor y su familia. Esta tarea queda a cargo de la disciplina antes mencionada: "La Ruralística debe determinar la mínima unidad poderal, las dimensiones de un poder modelo que sirve como norma para una legislación que regule ya sea el excesivo desmembramiento, ya sea el excesivo acumularse de los fundos en las manos de un solo propietario" (Gómez Gavazzo, ca. 1950). El tamaño debe ser definido partiendo del hombre, es decir de las posibilidades de trabajo del individuo entendido en asociación con otros iguales para conformar las colonias. Este cálculo le arroja un valor que debe estar entre las 4 y las 24 Há., según la integración familiar: la primera para padres y 4 hijos menores y la segunda para padres 4 hijos mayores y 2 menores.
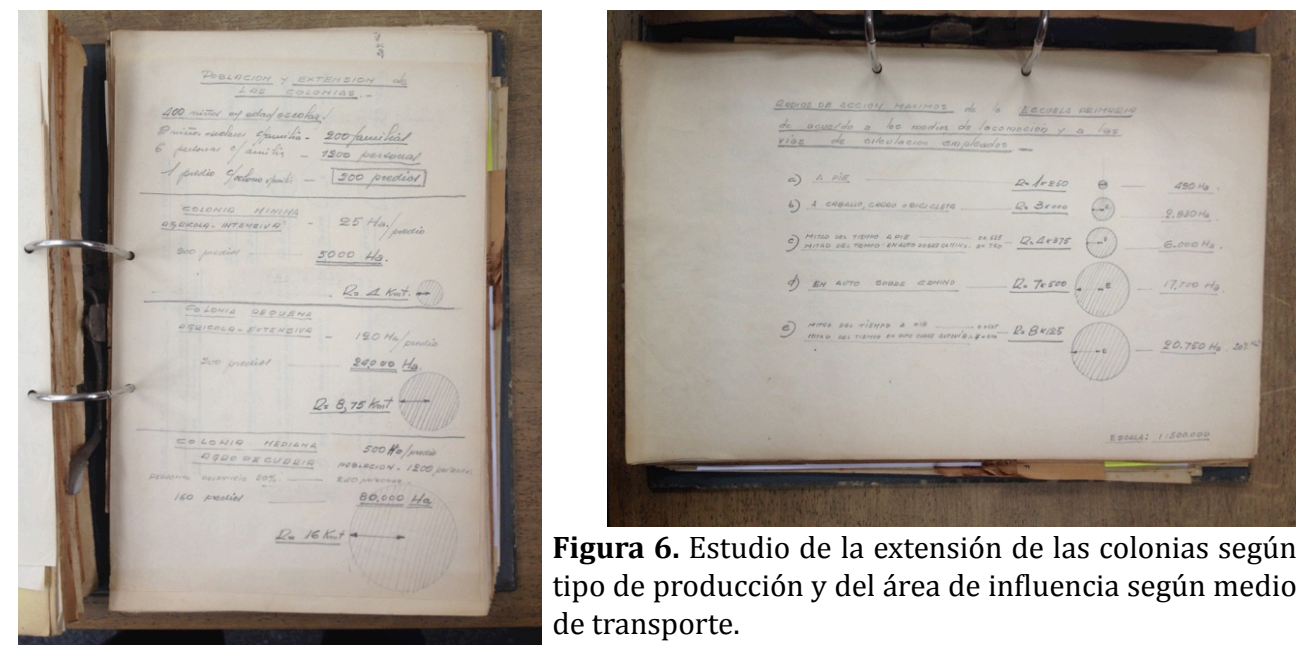

Figura 6. Estudio de la extensión de las colonias según tipo de producción y del área de influencia según medio de transporte. 
- De acuerdo a los tamaños de la unidad poderal, es posible, mediante la definición de una hipótesis del establecimiento de una escuela por colonia, precisar el tamaño final de la colonia según el tipo de producción a la que se dedica. También es posible delimitar el área de influencia o sea el territorio a su alrededor sobre el cual tiene incidencia dicha colonia. Para esto es necesario realizar una serie de cálculos geométricos y matemáticos que guardan relación con la teoría de la distancia-tiempo. Es decir la distancia que es posible recorrer según el medio de transporte utilizado, desde a pie hasta motorizado.

Todos estos estudios alimentarán el proceso de conformación de la Teoría de la Planificación Rural tal cual tomará solidez más adelante en el tiempo.

\subsection{El Seminario Regional de Asuntos Sociales de Porto Alegre}

En el año 1951, en el Seminario Regional de Asuntos Sociales, organizado por la Unión Panamericana en Porto Alegre se establecieron 4 temas de trabajo: Cooperativas, Educación Obrera, Servicio Social y Vivienda y Urbanismo (también denominada Vivienda y Planeamiento en la publicación resumen del Seminario). La Facultad envió como delegado al Arq. Carlos Gómez Gavazzo quien obviamente participó de la mesa de trabajo del último tema.

La presentación que llevó para exponer constaba de una exposición gráfica y una tesis escrita. Ambas son publicadas a su regreso en el número 2 de los Boletines Informativos del ITU. La exposición gráfica consistía en una serie de paneles que demostraban el Análisis del Expediente Comunal, una versión modificada para su adecuación al Uruguay de la Grilla CIAM de Bridgewater 1947.

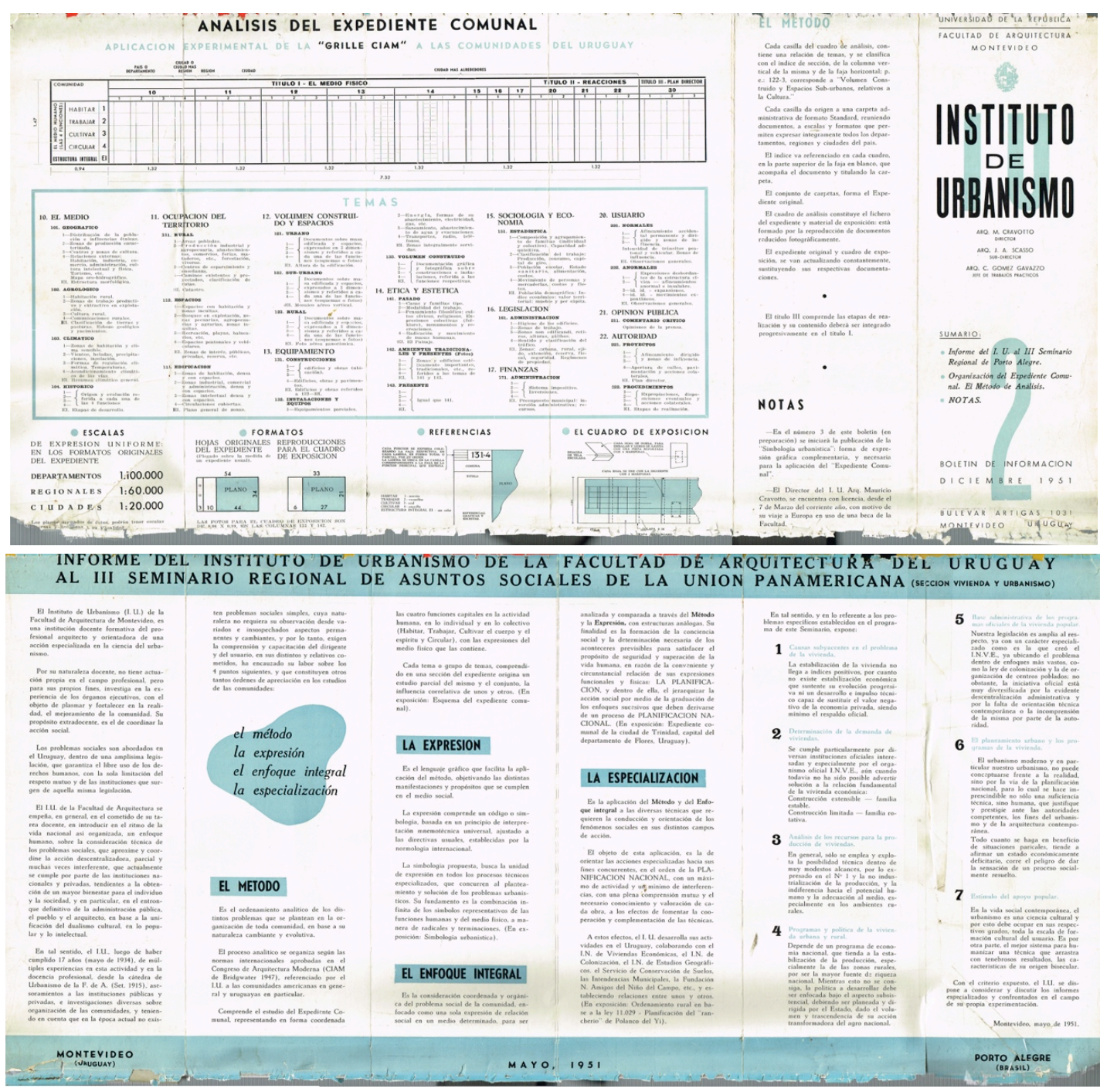

Figura 7. Boletín Informativo ํ2 2, diciembre 1951. 
Adicionalmente se exhibía la Simbología Urbanística propuesta para su uso universal que luego sería publicada en el Boletín $\mathrm{N}^{\circ} 7$ del ITU; una aplicación del Expediente Comunal a la ciudad de Trinidad, capital del departamento de Flores; y la planificación del rancherío de Polanco del Yí, realizada para el Instituto Nacional de Colonización a partir de las determinaciones de la Ley 11.029.

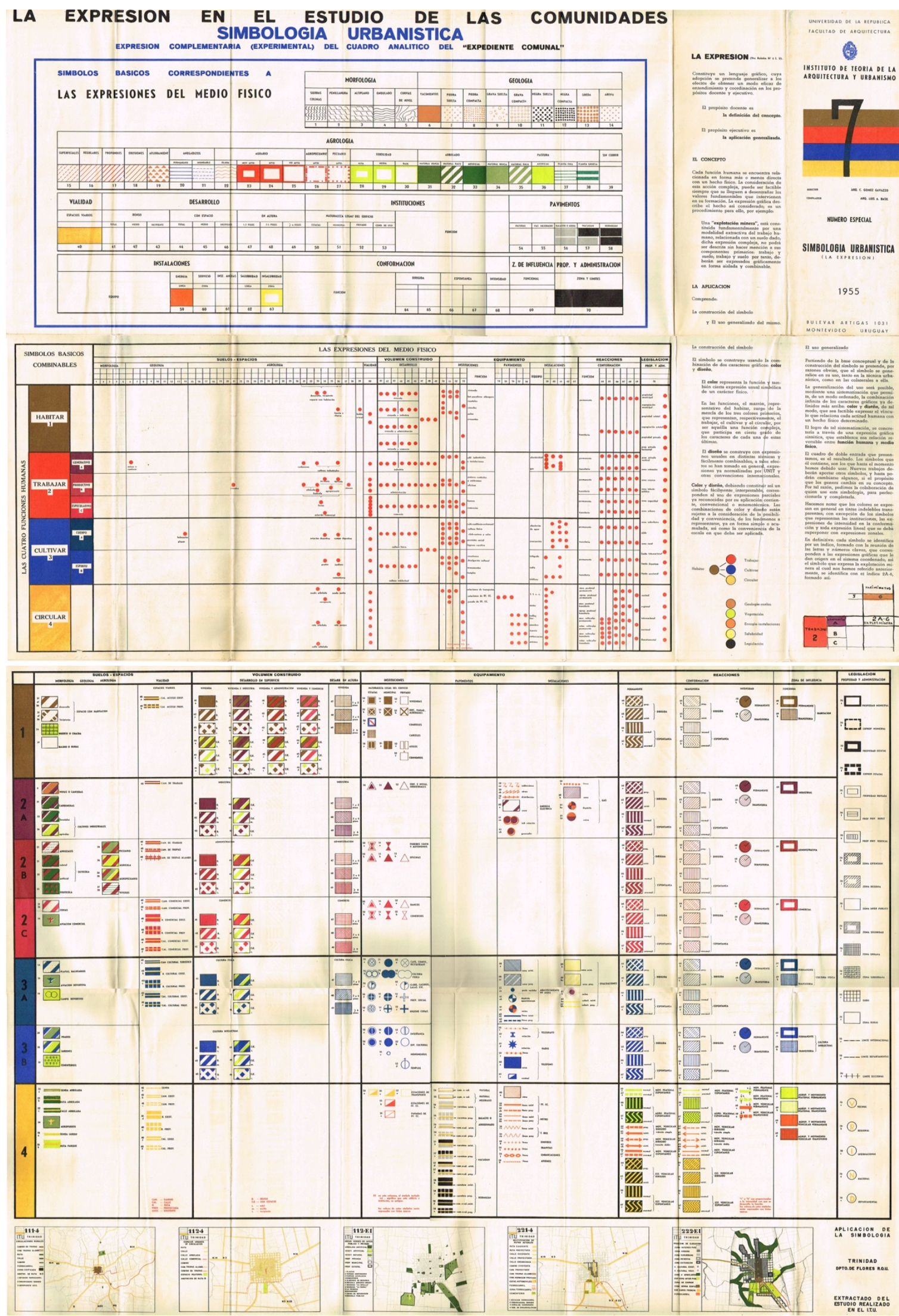

Figura 8. Boletín Informativo $\mathrm{N}^{\circ}$ 7, diciembre 1955. 
A la explicación de la exposición gráfica se le dedicó una tarde entera según el informe que Gómez Gavazzo presenta a la Facultad a su regreso. Recibió comentarios muy elogiosos y la solicitud de envío de copias por parte de varias delegaciones de países, así como por la propia organización -la Unión Panamericana- que se mostró muy interesada en establecer un criterio común de organización y sistematización de los estudios que dieran cientificidad al análisis urbano.

El Expediente Comunal inicia así una recorrida por las oficinas planificadoras de administraciones y gobiernos de la región. No debe olvidarse que uno de los objetivos de los Seminarios era difundir metodologías y procesos a técnicos que tuvieran responsabilidades en el hacer.

El objetivo de la Sección [Vivienda y Planeamiento] era servir de centro de asistencia técnica, investigación e información a organismos e instituciones públicos o privados de los países miembros [...] El programa de la División se desarrolla por medio de misiones de consulta enviadas a los países que solicitan los servicios; por la publicación y amplia distribución de monografías técnicas, informes, boletines, estudios de investigación, publicación de artículos preparados a través de un activo intercambio de información técnica [...] (Unión Panamericana, 1952).

La tesis escrita presentaba los alcances de la tarea emprendida por el ITU en nuestro país, así como una breve explicación del sentido de lo exhibido en la exposición gráfica. Nuevamente predomina el objetivo de desarrollar métodos ordenados y racionales que resulten deterministas a la hora de tomar decisiones para la acción. Y siempre con la intención de que estos métodos fueran universales.

Resulta visualizable también el proceso de enriquecimiento que los métodos de acción de Gómez Gavazzo tienen a partir de éste Seminario. Gran parte de los enfoques expuestos y que figuran en el documento impreso del Informe Final, resultan insumos para trabajos posteriores, ya sea afianzando posiciones que ya se tenían, o generando algunas nuevas, en particular en torno a los métodos o procedimientos a llevar a cabo. A su regreso recomienda las instancias de debate para ser realizadas en nuestro país sobre aquellos temas nacionales que requieran de opiniones especializadas diversas. Así lo mantendrá durante los años siguientes, poniéndolo en práctica e impulsándolo siempre que fuera posible. Asimismo en la dinámica de relacionamiento interinstitucional, algo que visualizó en toda su potencialidad en este Seminario, al haber delegaciones de instituciones variadas representando a cada país y poder observar la conveniencia de acumular los aportes de los diferentes técnicos especializados. Esta conveniencia se traduce en el afán de relacionamiento hacia fuera que impone al ITU a partir de asumir la Dirección.

Por último, el espíritu moderno y fiel a la línea ciamística que se trasluce en los debates y los enfoques de las mesas y conferencias, lo afirman en su posición, que no era estrictamente la predominante en el ITU. Tanto Cravotto como Scasso, los anteriores directores del Instituto, se habían formado en los inicios del Urbanismo, con una visión más estetizante y embellecedora, aún cuando participaban del espíritu moderno. Gómez Gavazzo, que había trabajado en el estudio de Le Corbusier unos meses entre 1933 y 1934, se afirma fuertemente en las doctrinas ciamísticas e impulsa esta línea al menos hasta mediados de los 60 .

\section{La Teoría del Ordenamiento Rural}

La Teoría del Ordenamiento Rural es una compleja combinación de aspectos ideológicos y procedimientos técnicos referidos a cuestiones sociales, económicas, matemáticas, espaciales, etc., que permiten operar racionalmente sobre el territorio para transformarlo con un objetivo concreto. Presentada en el libro Planificación Rural en el Uruguay (inédito de 1952), es una exposición completa de las intenciones, objetivos y modos de hacer para transformar el territorio del Uruguay por completo. Es decir que consiste en una teoría cuya aplicación constante y gradual a largo plazo, sería capaz de modificar completamente la matriz de poblamiento y uso del suelo de todo el país.

Al definir los postulados iniciales de la Teoría manifiesta que "acondicionar el territorio es acondicionar a la comunidad y ello supone el análisis y la integración del medio físico y las funciones 
humanas" (Gómez Gavazzo, 1952). 0 dicho de otra manera transformar el territorio implica la transformación de sus pobladores y esto debe realizarse con un detallado estudio que permita conseguir una comunión entre el suelo y las actividades desplegadas en él. Esta visión de partida asume y deja evidente el compromiso que la tarea tiene por detrás: es posible poner en práctica técnicamente un nuevo imaginario para el ámbito rural que trascienda las problemáticas existentes. Aquella campaña latifundista salpicada de rancheríos misérrimos está disponible para ser imaginada de otra forma. Esa es la tarea a emprender.

Y más adelante agrega: [...]

[...] La civilización es el elemento natural que impone la modalidad de la acción económica y la política. La acción económica del hombre es el fundamento de la acción social. La política es el procedimiento adecuado para resolverla (Gómez Gavazzo, 1952).

Este postulado convoca a iniciar mediante procedimientos políticos, es decir acuerdos de la comunidad sobre sus problemáticas y los modos de encauzarlas, las transformaciones de las actividades económicas y sociales que impongan la civilización buscada. Lo cual no parece desacertado en medio del panorama existente por esas épocas en el medio rural.

La teoría parte de problematizar algunas cuestiones básicas que en general habían sido tomadas parcialmente e incluso se habían arribado a respuestas automáticas que conviene analizar.

Primero punto. El tema del afincamiento rural había sido confundido con el tema de la vivienda rural, es decir que se habían puesto en marcha mecanismos que atendieran a resolver las peores condiciones de la unidad de habitación familiar en el ámbito rural, pero esto no estaba en consonancia con un verdadero afincamiento. Gómez Gavazzo afirma al respecto que [...]

[...] la necesidad de orientar la acción hacia fines inmediatos para resolver problemas perentorios y asaz complejos, no han permitido dilucidar tal vez esta cuestión, desconociéndose así la importancia capital que ella encierra, ya que de aclararla significaría introducir una base conceptual en la formulación de planes, que aunque de ejecución más larga, no llegaría a comprometer soluciones inmediatas. [...] Es que el afincamiento representa una forma particular de consumo; pero de un consumo que no observe solamente la riqueza producida en el medio al cual pertenece, aún cuando en buena parte depende de ella. Pero lo que sí puede afirmarse del aporte dado al problema por ambas posiciones, es que se llega a confundir afincamiento con vivienda, es decir, con un elemento del mismo cuya naturaleza si bien revela bastante de sus propios caracteres, no podrá nunca abarcarlos todos, desde que la vivienda es consumo y el afincamiento es a la vez producción y consumo (Gómez Gavazzo, 1952).

Es claro entonces que no es razonable anteponer la producción al afincamiento, ni tampoco la vivienda al afincamiento. En todo caso es necesario operar mediante planes - de largo plazo y con una fuerte base conceptual - que enfrenten la temática completa del afincamiento, el cual es complementario de la producción y conformador de la comunidad. Allí el tema de la vivienda deja de ser una preocupación en relación a un núcleo familiar y pasa a ser colectivo. Algo que ahora es visto como un error en el cual él mismo había caído con el rancho experimental de San José, al inicio de sus preocupaciones por lo rural, aún cuando el estudio tomaba en consideración algunos aspectos del entorno inmediato productivo.

Segundo punto. El modo de vida de la ciudad y del campo era completamente diferente en nuestro país. La localidad principal, Montevideo, concentraba la mayor parte de la población y los servicios nacionales y las ciudades medianas y pequeñas, contenían igualmente una dotación de servicios mínimamente adecuada. En tanto el medio rural carecía por completo de infraestructuras básicas (rutas electricidad, etc.), así como de equipamientos colectivos esenciales (salud, ocio, etc.). El afincamiento en el medio rural era casi una experiencia de supervivencia y la lejanía del Estado era manifiesta, con la noble excepción de la escuela rural que constituía la única presencia visible.

Esta diferencia de ámbitos es un error de concepción según Gómez Gavazzo y esto es lo que debe transformarse si el objetivo es promover el afincamiento rural. [...] 
[...] La habitación y el trabajo, siendo en principio funciones humanas fundamentales, sólo llegan a ser expresiones inequívocamente reveladoras del afincamiento, cuando van acompañadas de los necesarios aportes culturales y los posibles y convenientes medios de circular. Es este el único modo de concebir una estructura socio-física estable y cuyo ejemplo queda patentizado por la estabilidad del afincamiento urbano, que constituye la ciudad. No existe razón para que el afincamiento rural deba responder a otras características (Gómez Gavazzo, 1952).

Tercero punto. Para que el afincamiento sobre el territorio sea razonable y adecuadamente distribuido es necesario incorporar la noción de distancia-tiempo, otra teoría profundamente estudiada por el ITU y que ya estaba presente en los análisis de la Ley de Colonización 11.029.

La idea de localizaciones como baricentros ubicados en el territorio y definiendo un área de influencia, tiene evidentes relaciones con la Teoría de los Lugares Centrales de Walter Christaller, a la vez que incorpora el modo de movilidad para definir diferentes niveles de influencia. [...]

[...] El baricentro lo es de un área de territorio de cuyos distintos lugares los separa una distancia susceptible de ser salvada en condiciones compatibles con el esfuerzo que tal acción demanda al usuario y el interés que este posea para llenar su necesidad. [...] Desde luego no ha de olvidarse que la traza y caracteres del camino ha dependido inicialmente del uso y propósitos del impulso. [...] De este modo el camino -como hecho físico-es un verdadero jalón en el cuadro de la evolución del territorio (Gómez Gavazzo, 1952).

A partir de estos conceptos elabora el modelo de las Unidades Básicas de Explotación Rural que constituye el modelo teórico aplicable a los nuevos afincamientos que deberían instaurarse. Las categorías son las previstas en la Ley de Colonización 11.029: Ganadera o Forestal, Agropecuaria, Agrícola extensiva y Agrícola extensiva. De allí se deducían los tamaños adecuados en función de las unidades poderales adecuadas estudiadas anteriormente y se establecían las separaciones pertinentes en función de la Teoría distancia-tiempo.

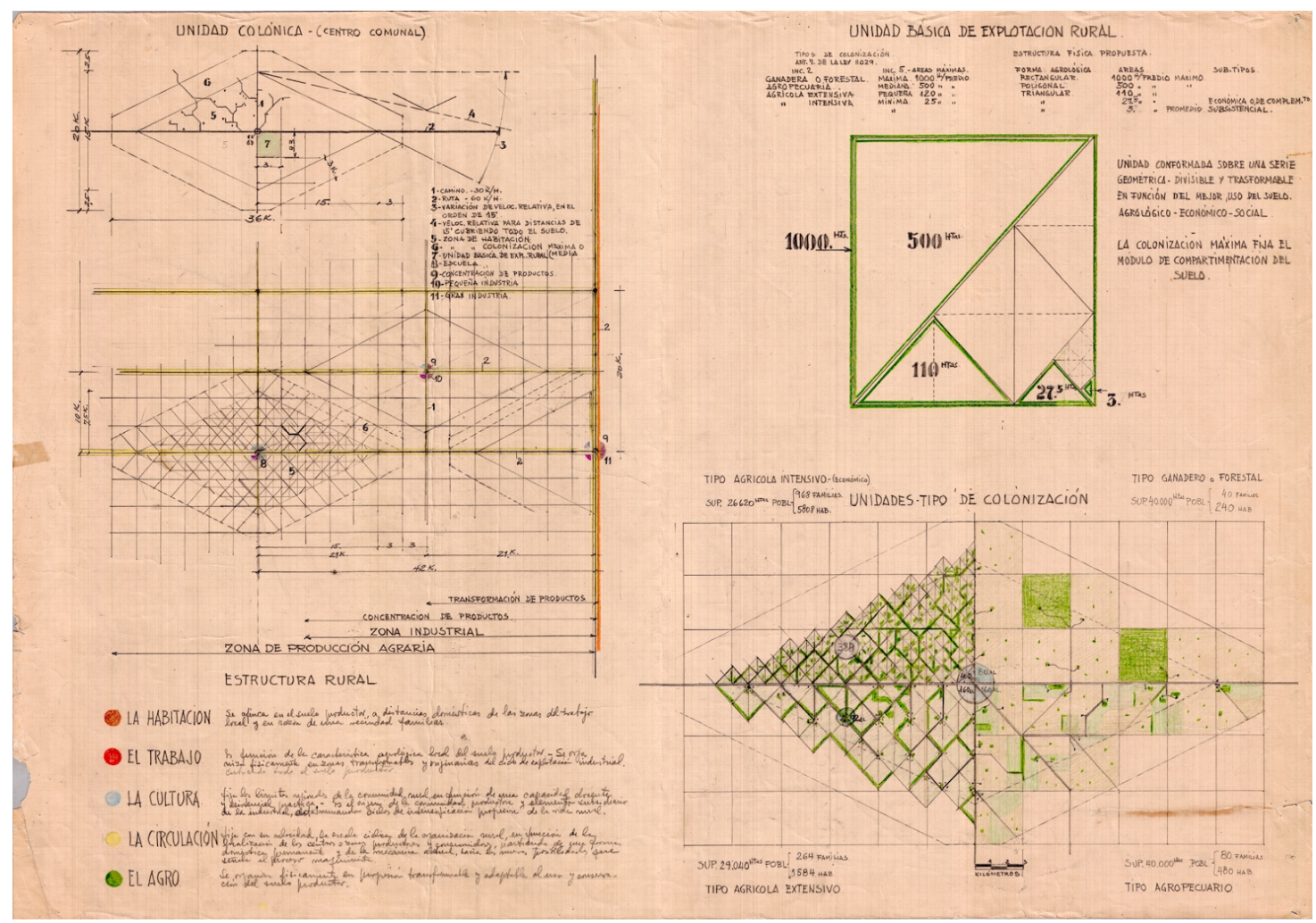

Figura 9. Modelo de Unidades Básicas de Explotación Rural.

El modelo es claro en la interrelación entre las diferentes categorías de producción y la manera en que pueden articularse estos rombos de 36×20 km. en el territorio. El gráfico de abajo a la derecha articula los 4 posibles tipos de colonias representados ocupando una cuarta parte del 
rombo para demostrar la abstracción del modelo teórico y sus capacidades de adaptabilidad. El gráfico del medio a la izquierda representa el territorio con la asociación de colonias productivas en régimen de vecindad y se titula Estructura Rural, dejando en claro que este modelo será el que se imponga sobre el suelo infinitamente determinando la forma de su uso.

De la lectura completa del libro Planificación Rural en el Uruguay surgen otra gran cantidad de temas y reflexiones acerca del modelo propuesto, aspectos sobre los que se extenderá y profundizará la tesis en elaboración. Hasta aquí se ha expuesto lo mínimo imprescindible para presentar el modelo y fijar las argumentaciones en torno a la estructura general propuesta para el territorio rural.

Queda aún un componente esencial para comprender cabalmente el imaginario propuesto por estas modelizaciones: hacer un acercamiento a un caso concreto de centro colónico. Es decir visualizar con claridad la materialidad y su modo de uso planteado para uno de los rombos propuestos. Esto es posible de realizar dado que en el entorno de 1952 y 1953 Gómez Gavazzo desarrolló desde el ITU un Plan concreto para el área de las colonias del noroeste del Uruguay. Este Plan está profusamente graficado y se conservan las láminas que presentan la aplicación de la Teoría en relación a la ubicación de las colonias de Chapicuy y Tangarupá entre las ciudades de Salto y Paysandú. Adicionalmente existe otro conjunto de láminas que desarrollan el Proyecto específico para la colonia de Chapicuy sobre la cual se hará un análisis a continuación.

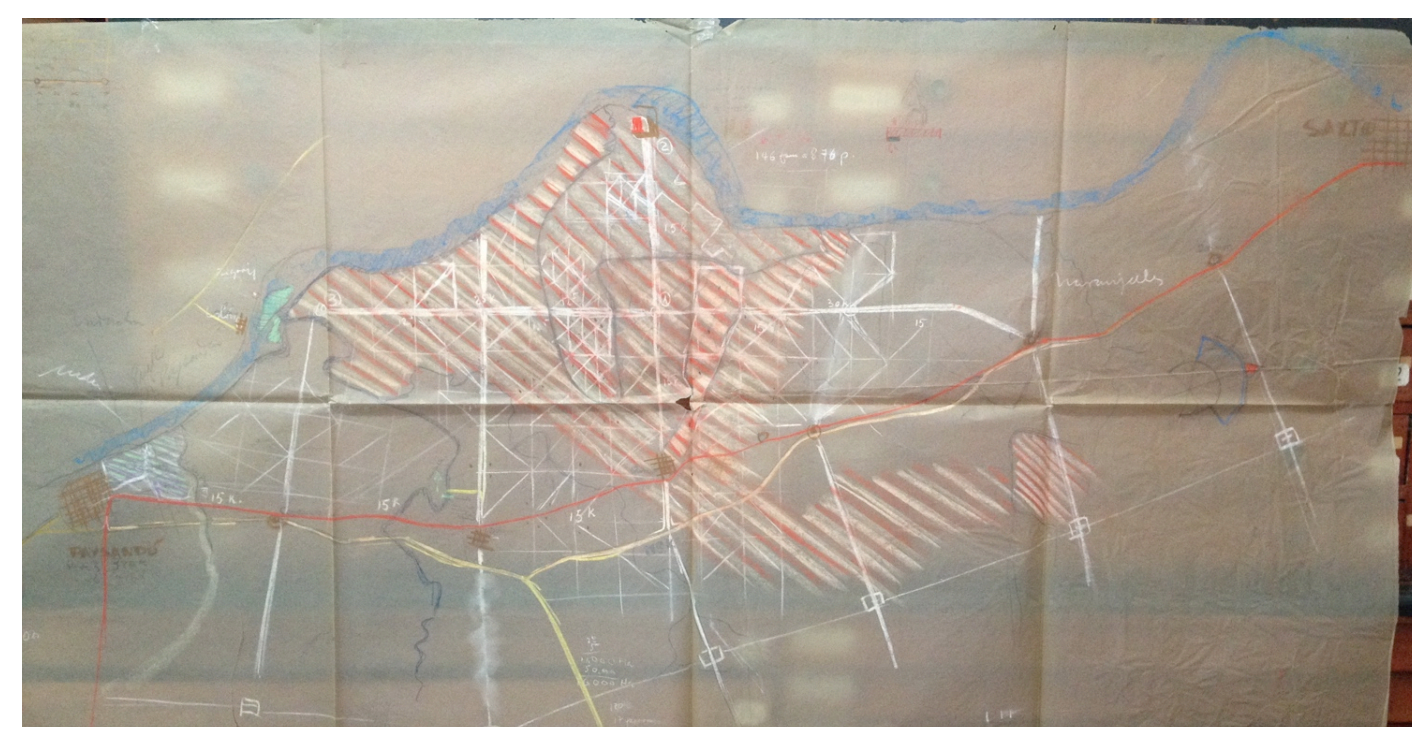

Figura 10. Teoría de la movilidad distancia-tiempo aplicada a los centros colónicos de Chapicuy y Tangarupá.

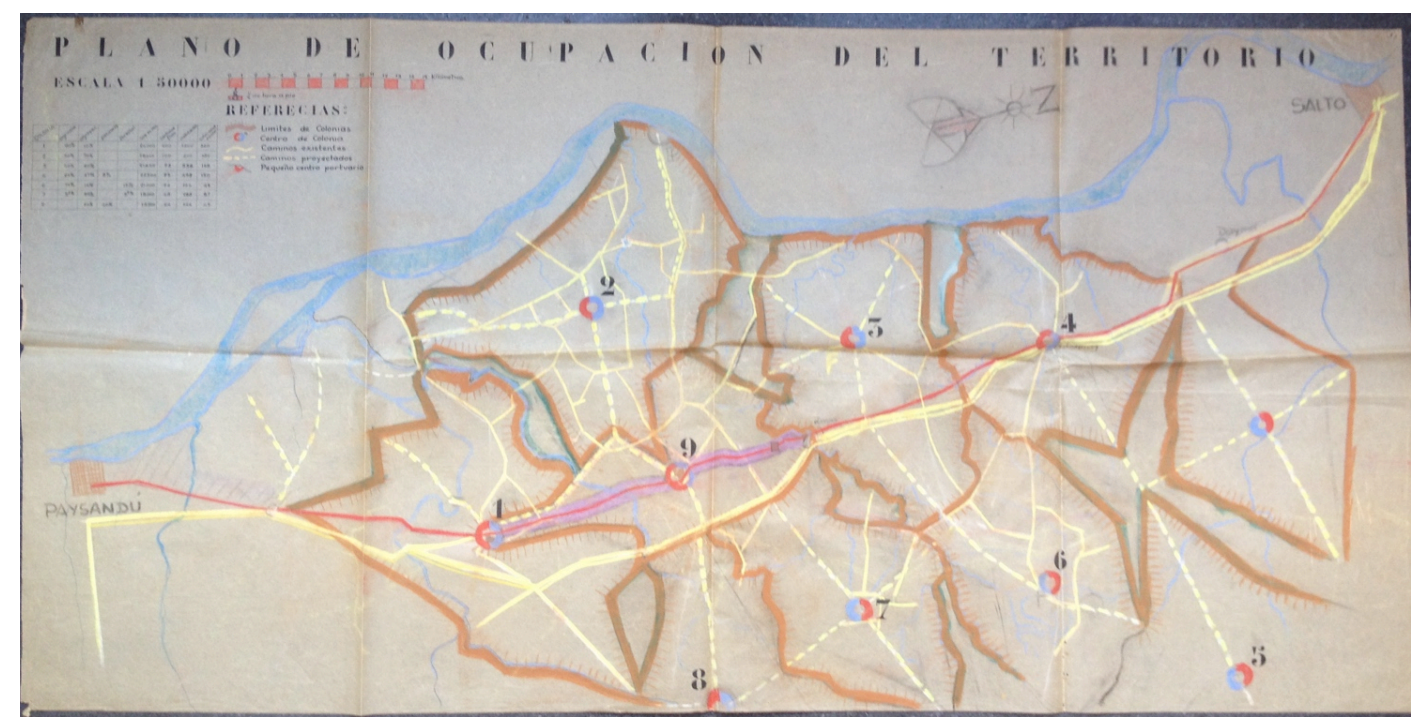

Figura 11. Ocupación del territorio en la zona de Chapicuy y Tangarupá, véase los rombos adaptándose al lugar. 


\section{El Caso de Chapicuy}

El proyecto para Chapicuy asociado al Plan para la región, se convierte en la oportunidad para materializar todo lo estudiado, analizado y decantado durante casi 20 años. No en vano las carpetas de trabajo contienen grandes listas de información a conseguir, de faltantes, de estudios a realizar, de solicitudes de información a casi cualquier institución pública que hubiera medido o relevado algún dato del lugar. Lo que demuestra el empeño puesto en que éste proyecto fuera demostrativo y abarcativo. En un solo caso se compendiaría la llegada a tierra de varias teorías y conceptualizaciones. Un gran compromiso para el primer afincamiento modelo que debía realizarse además, como alternativa a un proyecto elaborado por el Instituto de Colonización.

Contraponiendo las imágenes se evidencian las diferencia a primera vista, el proyecto del INC (arriba) intenta retomar trazas existentes y resuelve una subdivisión de padrones de manera convencional. El del ITU (abajo) concentra la población sobre la franja E-O de la conexión vial principal, donde acomoda además los servicios sociales y colectivos. La población trabajadora es alojada en 20 lotes de viviendas individuales (de 25 x $100 \mathrm{~m} \mathrm{c} / \mathrm{u}$ ) con un sector de huerta familiar detrás $y$ un gran lote de vivienda colectiva. En los primeros irían las familias de jornaleros permanentes, mientras en el segundo se alojarían las familias de peones temporales casados y los peones solteros.

Figura 12. Contraposición de propuestas del INC y del ITU.

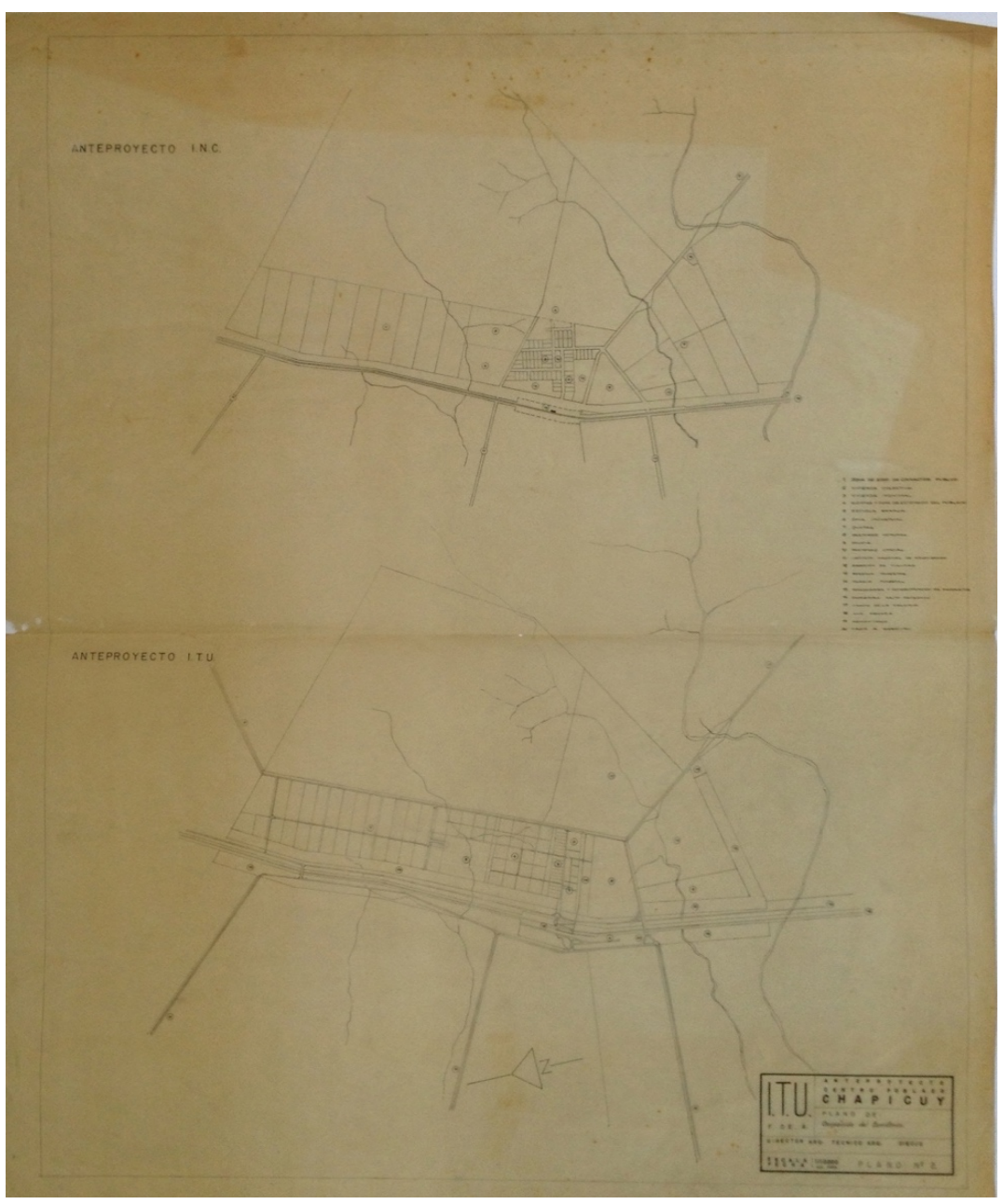

De esta manera unos 830 habitantes se distribuirían en una faja de 600 metros de largo 100 metros de ancho, lo cual arroja un valor de unos 140 habitantes por Há., un valor sin dudas interesante para un área rural, considerando que también se destina suelo a huerta familiar.

Esta densidad es posible en la medida que la población alojada en vivienda colectiva se ubica en bloques en el verde. Efectivamente el modelo de alojamiento para la población flotante, es decir aquellos que no tienen familia arraigada y los que vienen a la colonia para desarrollar tareas zafrales, es el más típico de raíz ciamística. Uno de los tantos croquis de ideación que se encuentran en las carpetas del proyecto lo demuestra: se dibujan con claridad 2 bloques de vivienda colectiva muy cercanos al mercado, las oficinas, el club y los servicios de salud. Estos dos bloques deberían tener unas 260 viviendas según el estudio de “determinación de la población” (Gómez Gavazzo, s/f).

Otros croquis que acompañan la propuesta enfatizan en los aspectos de segregación vial, un tema también muy caro a las inquietudes modernas. En efecto se define con precisión una separación del tráfico vehicular motorizado del de tracción a sangre. Asimismo se separa con cuidado la vía vehicular principal de la vía férrea. 


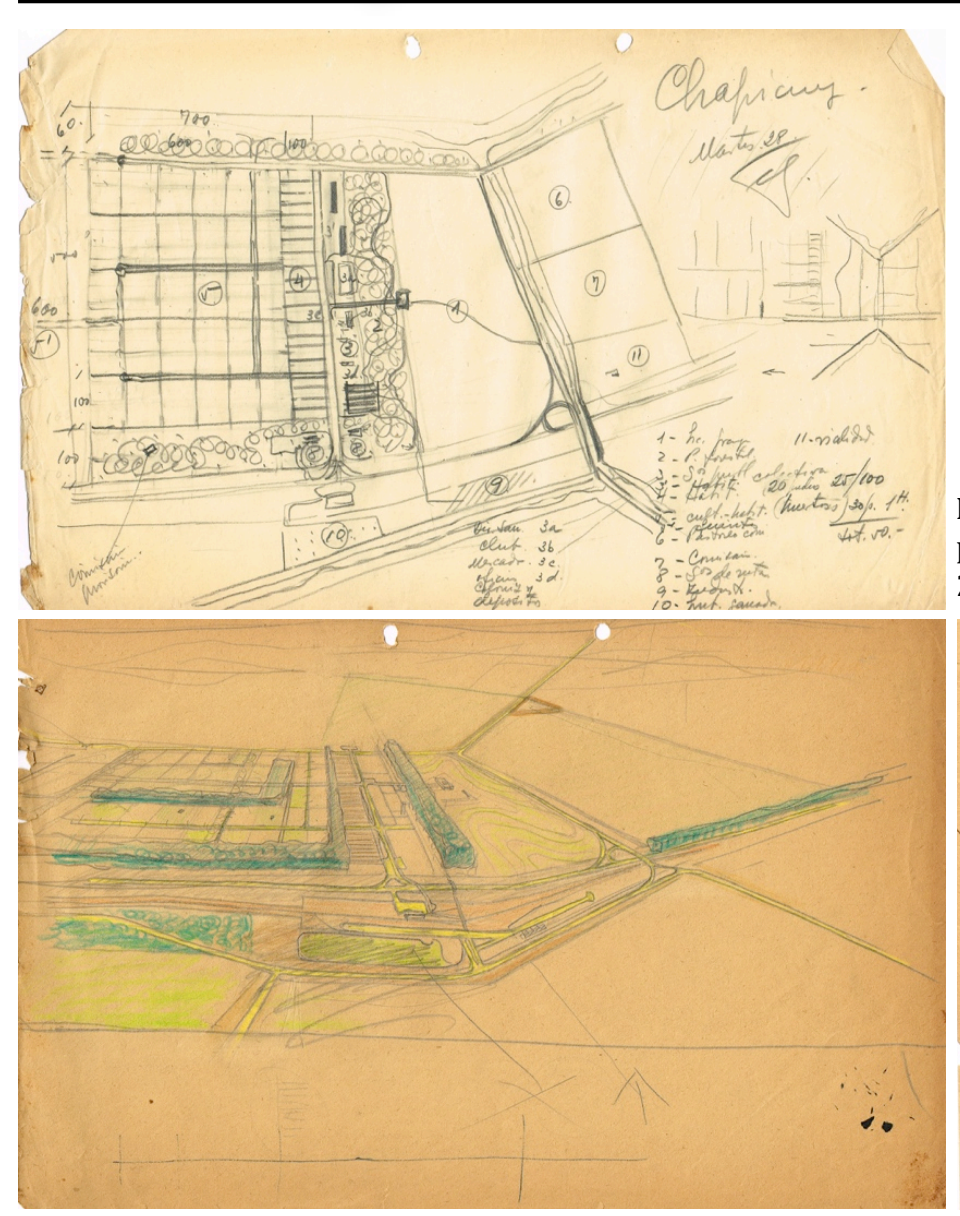

Figura13. Croquis de ideación del proyecto para la colonia de Chapicuy, arriba al centro los 2 bloques de vivienda.

En la zona oeste de la localidad, y coincidiendo con el nudo vial de acceso se conforma un último componente de actividad netamente productiva urbana: un centro de actividades industriales de 5 Há., un centro de acopio de mercancías, un área de silos, otras instalaciones de movilidad, estacionamientos, terminal de ferrocarril, etc., acumulando en ese sitio, la dinámica de la actividad más febril del centro colónico.

Y para mediar con el modo de transporte a pie, una serie de pasarelas peatonales elevadas permiten el cruce a desnivel de la ruta, la vía férrea y el área productiva, conectándose con el gran parque que recorre el límite sur del proyecto. Este parque con un trazado de sendas peatonales paisajísticas contiene a su vez las instalaciones deportivas y se presenta a manera de parque urbano, es decir como una segunda naturaleza completamente artificializada.

Si todas las operaciones anteriores son radicales para el sitio en que se implantan, resulta sumamente curiosa esta última de parquización urbana, dado que el centro colónico se ubica en el medio del campo productivo. Si bien las preocupaciones por el paisaje ya estaban presentes en Scasso y en los propios intereses de Cravotto - basta recordar los estudios de modos organizativos y formales de las aldeas vernaculares ensayados en las propuestas para el barrio del Cerro de Montevideo-, la intención de Gómez Gavazzo parece ser otra: el objetivo es urbanizar la vida rural. Llevar los modos de vida y de representación social urbanos al medio rural para conformar un nuevo imaginario de futuro, que estructure el medio productivo fundamental de nuestro país.

No en vano en el proyecto de Chapicuy se incluyen bloques residenciales, zona industrial, comercios, correo, telégrafo, juzgado, banco, escuelas, club, cine, teatro, policía, salud pública, zona de deportes, estacionamiento vehicular, estación de ómnibus y de trenes, estación de servicio, cruces a desnivel vehiculares y peatonales, parque forestal, entre otros. El programa está definido con transparencia y el objetivo parece ser claro: la transformación del habitante rural en un sujeto moderno. 


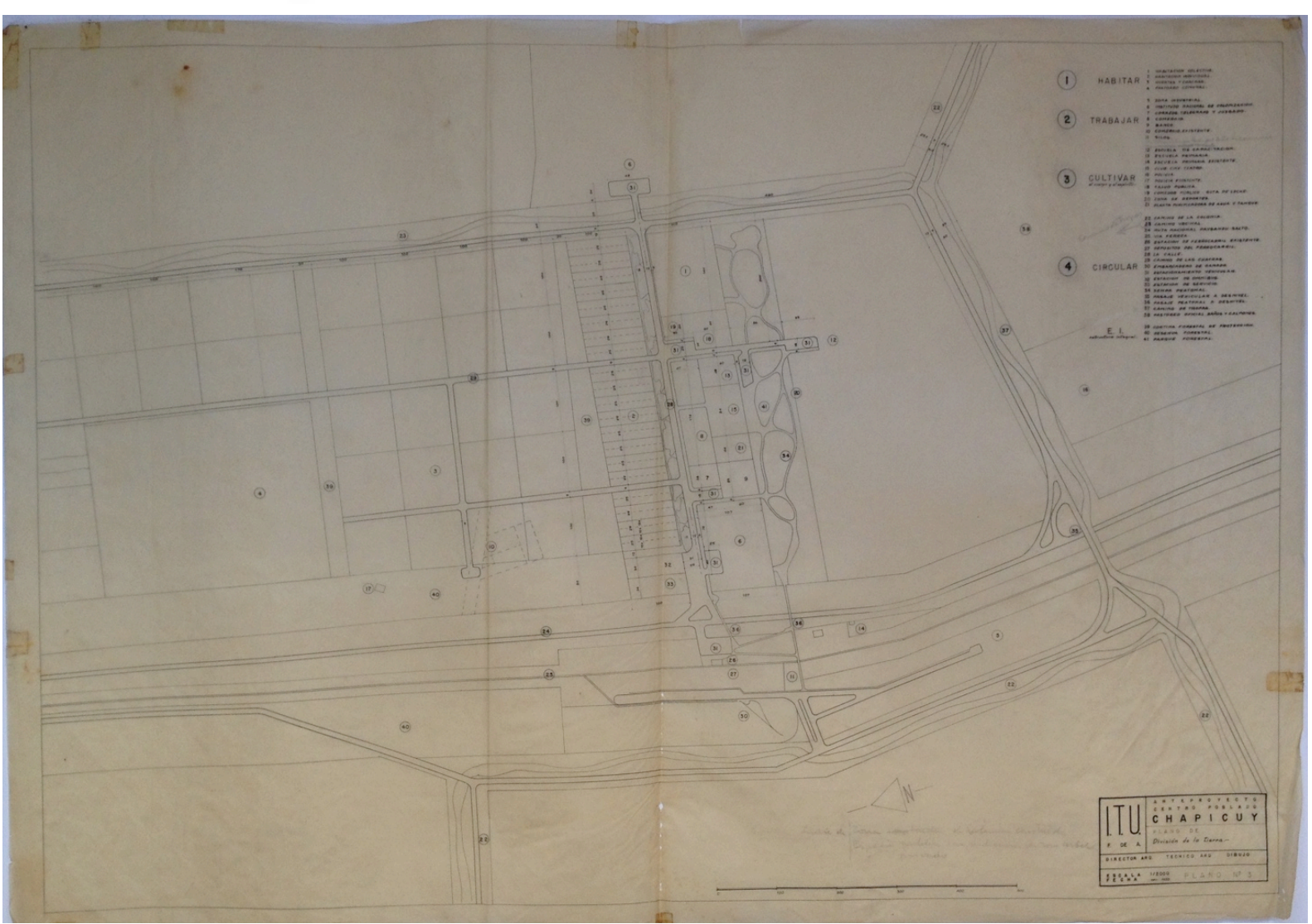

Figura 14. Plano final del proyecto para la colonia de Chapicuy (noviembre 1953).

\section{Referencias}

De Mattos, C. (1979, agosto) Planes versus planificación en la experiencia latinoamericana, Revista de la Cepal.

Perez Caldentey et al. (2000). Raúl Prebisch (1901-1986). Un recorrido por las etapas de su pensamiento sobre el desarrollo económico. Santiago [Chile]: Cepal.

Gómez Gavazzo, C. (1934). Manuscrito original sobre la problemática del rancho nacional [Archivo Gómez Gavazzo, Carpeta 6]. Montevideo: Universidad de la Republica, Farq/ITU.

Gómez Gavazzo, C. (1945). Discurso para el Primer Congreso Nacional de Colonización [manuscrito original, bibliorato 151S, Archivo Gómez Gavazzo]. Montevideo: Universidad de la Republica, Farq/ITU.

Gómez Gavazzo, C. (1945). Informe de la participación en el Congreso de Colonización [bibliorato 151S, Archivo Gómez Gavazzo]. Montevideo: Universidad de la Republica, Farq/ITU.

Gómez Gavazzo, C. (1950). Arquitectura del campo. Remodelación del naranjal salteño. Revista CEDA, n.19-20.

Gómez Gavazzo, C. (ca. 1950). Apuntes manuscritos sobre la Ley 11.029 [bibliorato 151S, Archivo Gómez Gavazzo]. Montevideo: Universidad de la Republica, Farq/ITU.

Gómez Gavazzo, C. (1952). Planificación Rural en el Uruguay [Archivo Gómez Gavazzo][libro inédito 1952]. Montevideo: Universidad de la Republica, Farq/ITU.

Gómez Gavazzo, C. (1953). La Planificación Regional y la Arquitectura [Discurso pronunciado el 9 de junio de 1953 en la Facultad de Arquitectura de la UDELAR, Montevideo, con motivo de la inauguración del curso de adiestramiento auspiciado por la Junta de Asistencia Técnica de Naciones Unidas]. Montevideo: Universidad de la Republica, Farq/ITU.

Gómez Gavazzo, C. (1959). Informe de la Comisión C" al Primer Congreso Pro-Reforma Agraria 13, 14 y 15 de noviembre de 1959 [Archivo Gómez Gavazzo, Carpeta 27]. Montevideo: Universidad de la Republica, Farq/ITU. 
Gómez Gavazzo, C. (1961). Reseña y comentario de la labor desarrollada en el Instituto de Teoría de la Arquitectura y Urbanismo del Uruguay [Conferencia dictada en el Seminario para Planeamiento, Tucumán, Argentina, 26 de octubre al 2 de noviembre de 1961][Archivo Gómez Gavazzo]. Montevideo: Universidad de la Republica, Farq/ITU.

Gómez Gavazzo, C. (s/f) [bibliorato 152, Archivo Gómez Gavazzo]. Montevideo: Universidad de la Republica, Farq/ITU.

Gurovich, A. (2009, junio) ¿A ver, qué sucede si...? Reflexiones en torno a un ensayo con modelos de simulación operativa en la enseñanza del Urbanismo. Revista de Urbanismo, $N^{\circ} 20$.

Instituto Interamericano de Cooperación para la Agricultura [IICA] (2003). El enfoque territorial del desarrollo rural. San José de Costa Rica: IICA.

Lattuada, M. (2014). Políticas de desarrollo rural en la Argentina. Conceptos, contexto y transformaciones. Revista Temas y Debates, 18 (27).

Lira, L. (2006). Revalorización de la planificación del desarrollo. Santiago [Chile]: Cepal.

Perez, M. et al. (2009). Planificación en territorios rurales. Proyección, Año 2009, no. 6.

Piñeiro, D., \& Moraes M.I. (2008). "Los cambios en la sociedad rural durante el siglo XX". en El Uruguay del Siglo XX [Tomo III. La Sociedad]. Montevideo: Editorial Banda Oriental.

Prebisch, R. (1949). El desarrollo económico de la América Latina y algunos de sus principales problemas El Trimestre Económico. Fondo de Cultura Económica, Vol. 16, No. 63 (3) 1949.

Quijano, A. (2014). Cuestiones y horizontes: de la dependencia histórico-estructural ala colonialidad/ descolonialidad del poder. CLACSO, 2014.

Rama C. M. (1971). Movimientos campesinos y problemas agrarios en el Uruguay de fines del siglo XVIII a nuestros días. Revista de Ciencias Sociales, 15 (2). [Centro de Investigaciones Sociales UPR Repositorio digital].

Ramela, P. A. (1961). La conferencia de Punta del Este. Revista de Política Internacional, n. 56.

Scasso J. A. (1935, mayo). El problema de la habitación rural. Revista La Propaganda Rural, n. 784.

Sevilla Buitrago, A. (2010). Territorio, "enclosure acts" y cambio social en la transición del feudalismo al capitalismo, Ciudades, n.13 [Revista del Instituto Universitario de Urbanística de la Universidad de Valladolid].

Unión Panamericana (1952). Seminarios Regionales de Asuntos Sociales [informe final].

Uruguay (1948). Ley 11.029 [del 12 enero de 1948 crea el Instituto Nacional de Colonización].

Uruguay, Ministerio de Salud Pública (1949). Relevamiento del Departamento de Contralor de Artrópodos. Montevideo: Ministerio de Salud Pública. 